\title{
Microfluidic chip for multiplex detection of trace chemical contaminants based on magnetic encoded aptamer probes and multi-branched DNA nanostructures as signal tags
}

\author{
Xixue Chen ${ }^{\mathrm{a}}$, Jiaqi Wang ${ }^{\mathrm{a}}$, Haoyu Shen*b, Xiurong Su${ }^{\mathrm{a}}$, Yuting Cao ${ }^{\mathrm{a}}$, Tianhua $\mathrm{Li}^{\mathrm{a}}$, Ning Gan*a \\ ${ }^{a}$ Faculty of material science and chemical engineering, Ningbo University, Ningbo, 31521, China \\ ${ }^{b}$ Ningbo Institute of Technology, Zhejiang University; Ningbo, 315100, China \\ *Corresponding Author Tel: + 86-574-66130129, 87609987; Fax: +86-574-88130130, 8760998. \\ E-mail address: hyshen@ nit.zju.edu.cn (Haoyu Shen); ganning@nbu.edu.cn (Ning Gan)
}




\section{Catalogue}

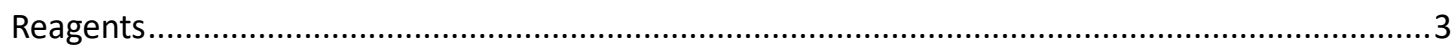

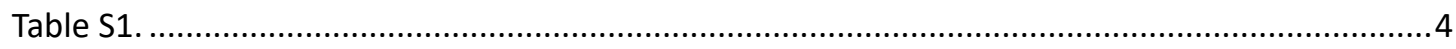

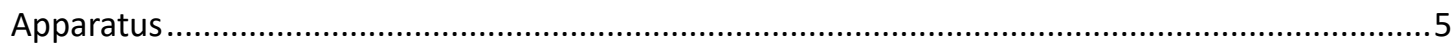

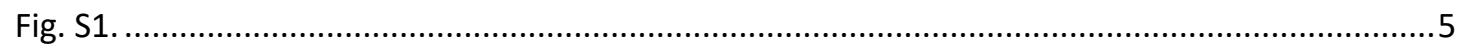

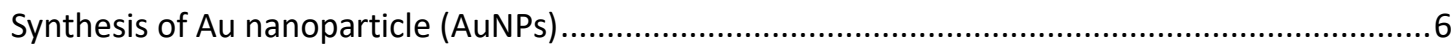

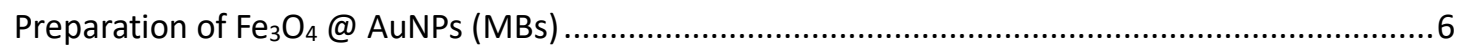

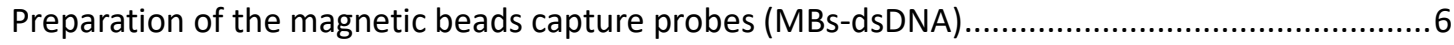

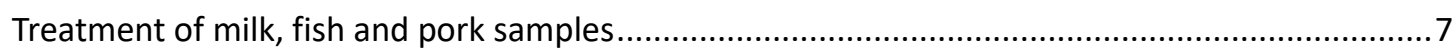

High performance liquid chromatography (HPLC) system for detection of E2 ….......................8

The calculation of the labeling concentrations for aptamer-primer complexs ............................8

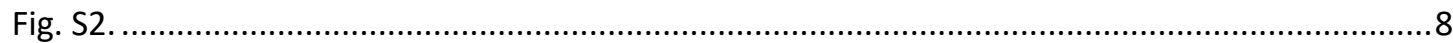

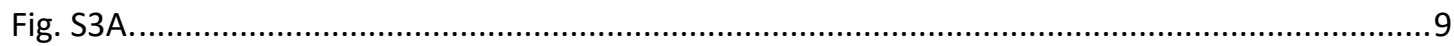

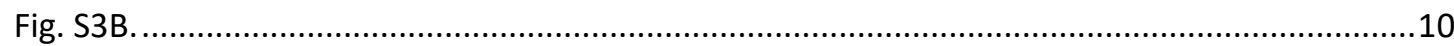

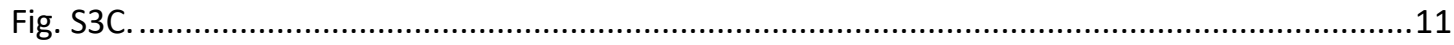

The explanation of purpose of gold nanoparticles and MBs ...................................................12

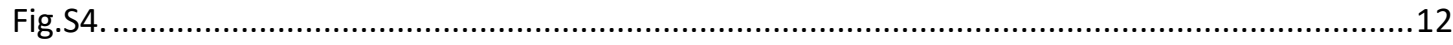

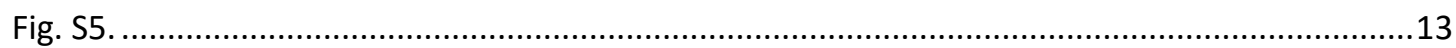

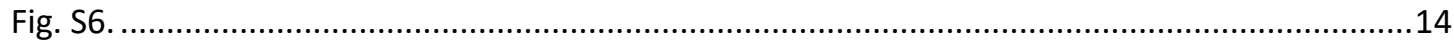

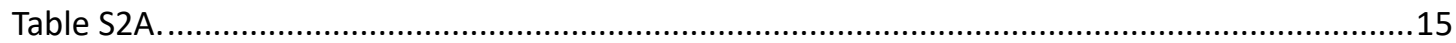

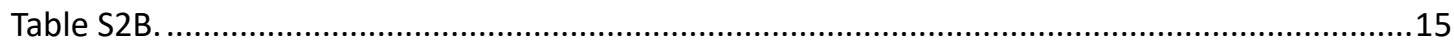

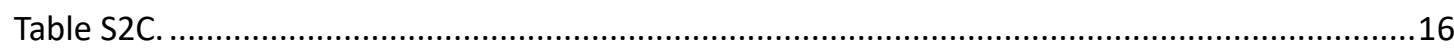




\section{Reagents}

Kanamycin (KANA), tetracycline (TET), chlortetracycline (CTC), gentamicin sulfate (GS), and chloramphenicol (CAP) were obtained from Sigma-Aldrich Co., Ltd (Milan, Italy). 17ß-estradiol (E2), bisphenol F (BPF), bisphenol A (BPA), and estriol (E3) were purchased from Sigma-Aldrich Co. (St Louis, MO, USA). $\mathrm{Pb}\left(\mathrm{NO}_{3}\right)_{2}, \mathrm{Cu}\left(\mathrm{NO}_{3}\right)_{2}, \mathrm{Zn}\left(\mathrm{NO}_{3}\right)_{2}$, and $\mathrm{Ca}\left(\mathrm{NO}_{3}\right)_{2}$ were purchased from Shanghai chemical reagent Co. Ltd (Shanghai, China). The tris (2-carboxyethyl) phosphine hydrochloride (TCEP) and 6-mercapto-1-hexanol (MCH) were purchased from Aladdin Co., Ltd (Shanghai, China). Fe3O4 nanospheres modified with amino (400 nm, 20 $\mathrm{mg} / \mathrm{mL}$ ) were purchased from Enriching Biotechnology, Ltd. (Shanghai, China). TE buffer solution ( $\mathrm{pH} 8.0$, stored at 2 to $8^{\circ} \mathrm{C}$ ), 25 bp base-pairs DNA ladder, DNA-500 separation buffer (stored at 2 to $8{ }^{\circ} \mathrm{C}$ ), and marker (stored at $-20{ }^{\circ} \mathrm{C}$ ) were all obtained from Shimadzu Co., Ltd. (Kyoto, Japan). SYBR Gold (Lot \# 1683656, 10000 concentrated) was obtained from Invitrogen Co, Ltd. (Thermo Fisher Scientific, USA). Phosphate buffer saline (PBS, pH 7.4, $0.1 \mathrm{~mol} / \mathrm{L} \mathrm{KH}_{2} \mathrm{PO}_{4}-\mathrm{K}_{2} \mathrm{HPO}_{4}, 0.1 \mathrm{~mol} / \mathrm{L} \mathrm{KCl}$ ) was prepared by standard methods. The pure water was purchased from Wahaha Company (Hangzhou, China). The enzyme-linked immunosorbent assay (ELISA) kit for kanamycin was purchased from Shanghai Yaji Biotechnology Co., Ltd. All reagents were analytical grade and were used without further purification. The oligonucleotide sequences (Table S1) were synthesized and purified by Sangon Biotechn. Co., Ltd. (Shanghai, China). 
Table S1. Sequences of oligonucleotides used in this method

\begin{tabular}{|c|c|}
\hline Name & Sequence $\left(5^{\prime}-3^{\prime}\right)$ \\
\hline Apt $t_{\text {KanA }}$ & AGA TGG GGG TTG AGG CTA AGC CGA ATC TCC \\
\hline PKANa & AGA GTG ATG GAG ATT CGG CTT A GC-SH- $\left(\mathrm{CH}_{2}\right)_{6}$ \\
\hline H1 & GCT AAG CCG AAT CTC CAT CAC TCT GTA AGT \\
\hline & $\begin{array}{l}\text { CTA GGT AGA GTG ATG GAG ATT CGC TAC AGT } \\
\text { TAT CCA TAT CAG }\end{array}$ \\
\hline $\mathrm{H} 2$ & $\begin{array}{l}\text { GCT ACA GTT ATC CAT ATC AGA GAG TGA } \\
\text { TGG AGA TTC GGC TTA GCG AAT CTC CAT CAC } \\
\text { TCT ACC TAG ACT TAC }\end{array}$ \\
\hline C-DNA KANA & CTG ATA TGG ATA ACT GTA GC \\
\hline $\mathrm{Apt}_{\mathrm{E} 2}$ & TGG GCC CTT TAC GGA CCG CGTG \\
\hline $\mathrm{P}_{\mathrm{E} 2}$ & 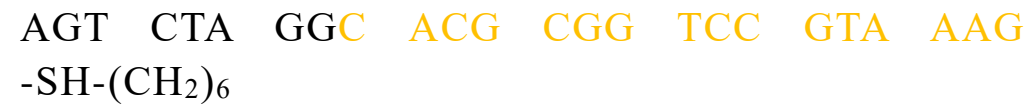 \\
\hline $\mathrm{H} 1^{\prime}$ & $\begin{array}{l}\text { CTT TAC GGA CCG CGT GCC TAG ACT CAA AGT } \\
\text { AGT CTA GGA CCT TCC TCC CGA GCT CGA TGT } \\
\text { CCA TAG TC }\end{array}$ \\
\hline $\mathrm{H} 2^{\prime}$ & $\begin{array}{l}\text { CGA GCT CGA TGT CCA TAG TCA GTC TAG } \\
\text { GCA CGC GGT CCG TAA AGG GAC CGC GTG CCT } \\
\text { AGA CTA CTT TG }\end{array}$ \\
\hline C-DNAE2 & $\begin{array}{l}\text { GAT CAC GAG ACT CGT GAT CGA CTA TGG ACA } \\
\text { TCG AGC TCG }\end{array}$ \\
\hline $\mathrm{S}_{\mathrm{pb}}^{2+}$ & $\begin{array}{l}\text { CAT CTC TTC TCC GAG CCG GTC GAA ATA GTG } \\
\text { AGT }\end{array}$ \\
\hline $\mathrm{PPb}^{2+}$ & $\begin{array}{l}\text { CGA TAA CTC ACT ATrA GGA AGA GAT GGT TGT } \\
\text { ATA GT-SH- }\left(\mathrm{CH}_{2}\right)_{6}\end{array}$ \\
\hline $\mathrm{H} 1 "$ & $\begin{array}{l}\text { CAT GTG ACA ATG TGC CGT CAG GTT GTA } \\
\text { TAG TAG GCA AAG TAA CTA TAC AAC CAT CTC } \\
\text { TTCCT }\end{array}$ \\
\hline $\mathrm{H} 2^{\prime \prime}$ & $\begin{array}{l}\text { ACT TTG CCT ACT ATA CAA CCA GGA AGA GAT } \\
\text { GGT TGT ATA GTA GGC ATG TGA CAA TGT GCC } \\
\text { GTCA }\end{array}$ \\
\hline $\mathrm{C}-\mathrm{DNA} \mathrm{Pb}^{2+}$ & $\begin{array}{l}\text { ATG CTA TCA GCG AGT GCT ATT AGC ACT CGC } \\
\text { TGA TAG CAT TGA CGG CAC ATT GTC ACATG }\end{array}$ \\
\hline
\end{tabular}

Note: Green nucleotides are complementary part of the primer and the aptamer of KANA. Yellow nucleotides are complementary part of the primer and the aptamer of E2. Blue nucleotides are complementary part of substrate ssDNA and enzymatic sequence of E2. Blod nucleotides are complementary part of C-DNAs and the arms of mHCR products. 


\section{Apparatus}

Transmission electron microscope (TEM, H600, Japan) was used to obtain TEM images. Scanning electron microscope (SEM, S3400 N, Hitachi, Japan) was used to acquire SEM images and energy dispersive X-Ray spectroscopy (EDX). The size distribution of nanoparticles was measured by a dynamic light-scattering (DLS) method using a Zeta-sizer Nano ZS (Malvern Instruments, United Kingdom). Inductively coupled plasma mass spectrometry (ICP-MS, Agilent 7700x) was used to analyze $\mathrm{Pb}^{2+}$. High performance liquid chromatography (LC-20AT HPLC) was used to analyze 17 $\beta$-estradiol. The centrifuge (3K15) was purchased from Sigma in Germany. The MCE-202 MultiNA instrument was purchased from Shimadzu Co. Ltd (Kyoto, Japan). The instrument was equipped with four microchips and one blue LED (470 nm; $20 \mathrm{~mA}$ ) apparatus as the light source, and the samples were detected at $525 \mathrm{~nm}$. The microchannel of the microchip was $23 \mathrm{~mm}$ in length, $104 \mu \mathrm{m}$ in width, and $48 \mu \mathrm{m}$ in depth (Fig. S1).

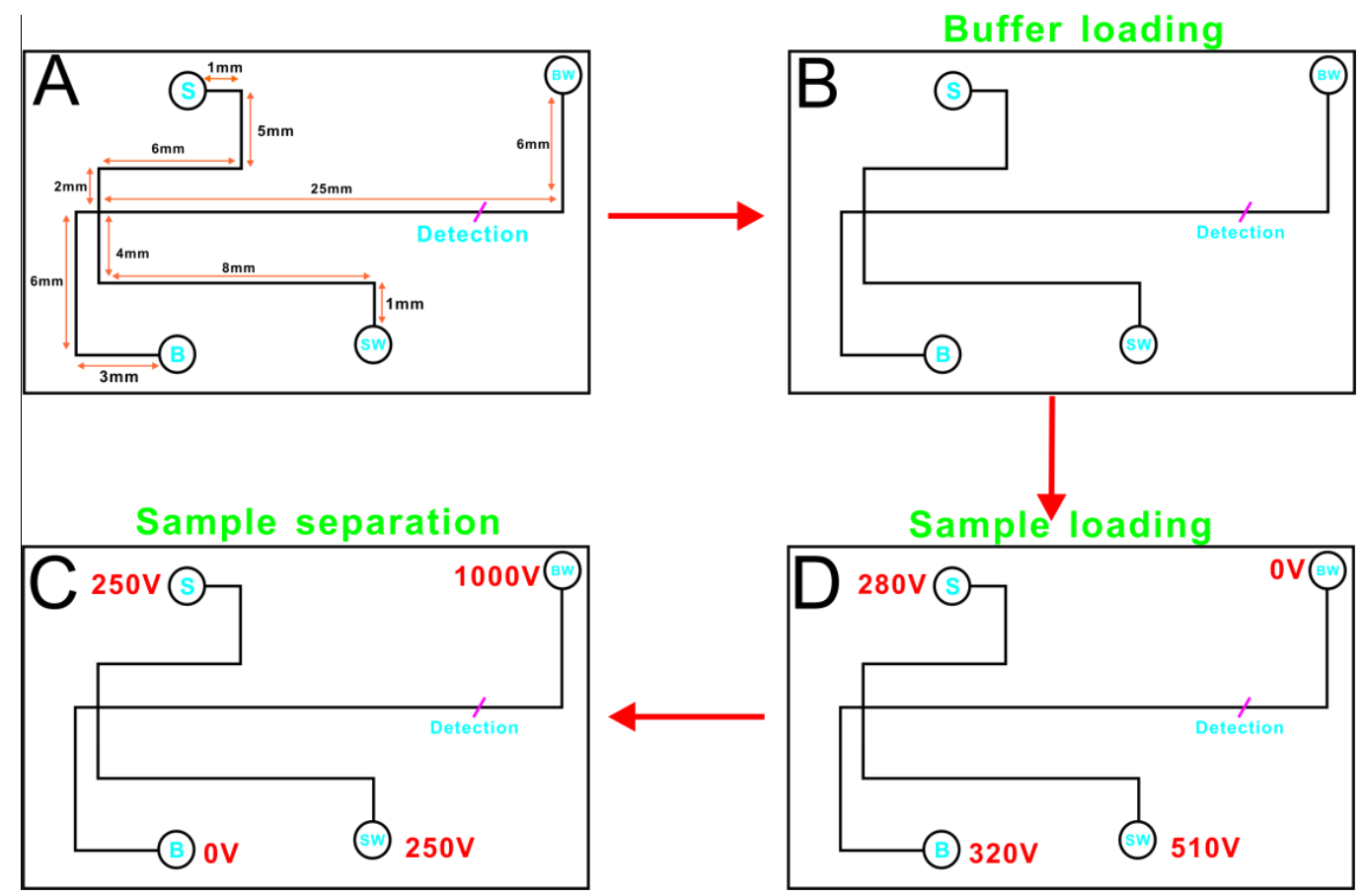

Fig. S1. Scheme illustration of sample analysis based on MC with (A) the photos of microfluidic chip; (B) buffer loading; (C) sample loading; (D) sample separation. 


\section{Synthesis of Au nanoparticle (AuNPs)}

$\mathrm{Au}$ nanoparticles (AuNPs) were synthesized using the procedures reported previously. In brief, first of all, $200 \mathrm{~mL}$ of $\mathrm{HAuCl}_{4}$ solution $(1 \mathrm{mmol} / \mathrm{L})$ was heated to boil under stirring in an oil bath pan. Then, $5 \mathrm{~mL}$ of trisodium citrate solution $(38.8$ mmol/L) was quickly injected into the $\mathrm{HAuCl}_{4}$ solution. The mixed solution was stirred thoroughly and heated for another 25 min until the solution color changed from grey to wine red. The solution was then cooled to $25^{\circ} \mathrm{C}$, and the product was stored at $4{ }^{\circ} \mathrm{C}$ before use.

\section{Preparation of $\mathrm{Fe}_{3} \mathrm{O}_{4} @$ AuNPs (MBs)}

First, $2 \mathrm{~mL} \mathrm{Fe}_{3} \mathrm{O}_{4}$ nanospheres $(20 \mathrm{mg} / \mathrm{mL})$ were dispersed in $5 \mathrm{~mL}$ double-distilled water by ultrasound about $10 \mathrm{~min}$. Then $180 \mathrm{~mL}$ of AuNPs solution $\left(2 \mathrm{mmol} / \mathrm{L}\right.$ ) was mixed with the final solid and shaken vigorously at $25^{\circ} \mathrm{C}$ about $8 \mathrm{~h}$. After removing the unreacted AuNPs of the supernatant by magnetic separation, the MBs were washed by deionized water and anhydrous ethanol. Finally, the the mixture was dispersed in $5 \mathrm{~mL}$ of $0.1 \mathrm{~mol} / \mathrm{L} \mathrm{PBS} \mathrm{(pH} \mathrm{7.4)} \mathrm{and} \mathrm{stored} \mathrm{at} 4{ }^{\circ} \mathrm{C}$ until use.

\section{Preparation of the magnetic beads capture probes (MBs-dsDNA)}

The primers $(10 \mu \mathrm{mol} / \mathrm{L})$ of three targets (KANA, E2, $\left.\mathrm{Pb}^{2+}\right)$ were incubated with TCEP $(10 \mathrm{mmol} / \mathrm{L})$ at a volume ratio of $1: 1.2$ for $1 \mathrm{~h}$ at $25{ }^{\circ} \mathrm{C}$ to activate the thiol group and cleave the disulfide linkage. At first, $800 \mu \mathrm{L} 10 \mu \mathrm{mol} / \mathrm{L}$ aptamers and 200 $\mu \mathrm{L} 10 \mu \mathrm{mol} / \mathrm{L}$ primers were mixed and incubated for 10 min at $37{ }^{\circ} \mathrm{C}$ in order to have no residual primers in solution. Then, $2 \mathrm{~g}$ dried MBs was immersed to $200 \mu \mathrm{L} 2$ $\mu \mathrm{mol} / \mathrm{L}$ TCEP-treated thiolated the DNA duplex of aptamers and primers at $4^{\circ} \mathrm{C}$ for $24 \mathrm{~h}$. Subsequently, they were purified by magnetic separation to remove the unconjugated DNA duplex and then $\mathrm{MCH}(1 \mathrm{mmol} / \mathrm{L})$ was used to block nonspecific binding sites for $2 \mathrm{~h}$. Finally, the products were rinsed with $0.1 \mathrm{~mol} / \mathrm{L}$ PBS buffer (10 $\mathrm{mmol} / \mathrm{L}$ phosphate, $0.1 \mathrm{~mol} / \mathrm{L} \mathrm{NaCl}, 0.05 \%$ Tween $20, \mathrm{pH} 7.4$ ) ten times. The mixture was stored at $4^{\circ} \mathrm{C}$ before use. 


\section{Treatment of milk, fish and pork samples}

Firstly, $20 \mathrm{~g}$ milk sample was centrifuged for $10 \mathrm{~min}$ at $4000 \mathrm{r} / \mathrm{min}(\times 1790 \mathrm{~g}) 4^{\circ} \mathrm{C}$ to remove the fat. Then, $2 \mathrm{~mL}$ of sodium nitroprusside solution and $2 \mathrm{~mL}$ of sulphate zinc solution were added and shaken. The mixture was centrifuged for $10 \mathrm{~min}$ at 4000 $\mathrm{r} / \mathrm{min}(\times 1790 \mathrm{~g})$ again. Finally, Finally, $5 \mathrm{~mL}$ of the supernatant was taken for detecting by our development method.

$2 \mathrm{~g}$ fish sample and $10 \mathrm{~mL}$ of extraction solution $\left(\mathrm{V}_{\text {acetonitrile }}: \mathrm{V}_{1 \mathrm{M}}\right.$ citric acid $: \mathrm{V}_{0.5 \mathrm{M}}$ EDTA-Na2 is 20:2:1) were placed in $50 \mathrm{~mL}$ centrifuge tube. The mixture was homogenized for 60s with an Ultra-Turrax TP 18/10 (Janke and Kunkel, Staufen, Germany). After centrifugation $10 \mathrm{~min}$ at $4000 \mathrm{r} / \mathrm{min}(\times 1790 \mathrm{~g}), 3 \mathrm{~mL}$ the supernatant was dried at $50-60^{\circ} \mathrm{C}$ under nitrogen atmosphere and then resolved in $100 \mu \mathrm{L}$ PBS for the detection by the developed method.

The $2.00 \mathrm{~g}$ pork and $10 \mathrm{~mL}$ of the extraction solution (trichloroacetic acid $(0.83$ $\mathrm{g} / \mathrm{L})$, Tween $20(0.0083 \%)$, methanol (16.7\%), mercaptoethanol (0.05\%) was placed in $50 \mathrm{~mL}$ centrifuge tubes. The mixture was homogenized for $5 \mathrm{~min}$ with an Ultra-Turrax TP 18/10 (Janke and Kunkel, Staufen, Germany). Then, it was centrifuged for $10 \mathrm{~min}$ at $4000 \mathrm{r} / \mathrm{min}(\times 1790 \mathrm{~g})$. Finally, $1 \mathrm{~mL}$ of the suspension was taken out and $4 \mathrm{~mL} 10 \mathrm{mM}$ PBS ( $\mathrm{pH}$ 7.4) was added. The resulting solution was stored at $4{ }^{\circ} \mathrm{C}$ prior to use. The extraction liquid in blank fish was to testify the matrix interference in real samples.

ELISA experiments was operated according to the specification and used as control for KANA. The ICP-MS method was from the Ningbo institute of industrial technology, CAS for $\mathrm{Pb}^{2+}$. 


\section{High performance liquid chromatography (HPLC) system for detection of E2}

The mobile phase including methanol and pure water was employed for separation with a flow rate of $1.0 \mathrm{~mL} / \mathrm{min}$ at $30{ }^{\circ} \mathrm{C}$. The following programs at the specific time were used for gradient elution: $40 \%$ methanol climbs to $50 \%$ at $0-2 \mathrm{~min}$ and kept the $50 \%(\mathrm{v} / \mathrm{v})$ methanol at 2-7 min. Quantitative analyses of compounds were performed using an PDA detector. The detection wavelength was set as $230 \mathrm{~nm}$ for E2.

\section{The calculation of the labeling concentrations for aptamer-primer complexs}

This illustrates that about 250 pmol aptamer-primer complexs were modified using MBs. This was calculated by the follow equation:

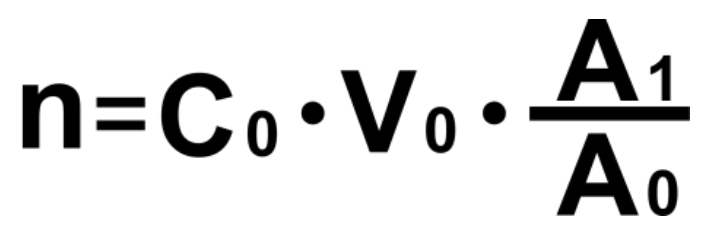

Where $\mathrm{C}_{0}$ represents the original concentration of aptamer-primer complexs $(\mathrm{pmol} / \mu \mathrm{L}), \quad \mathrm{C}_{0}=2 \mathrm{pmol} / \mu \mathrm{L}, \quad \mathrm{A}_{0}$ represents the absorbance of the original aptamer-primer complex, $\mathrm{A}_{0}=0.82, \mathrm{~A}_{1}$ represents the absorbance of aptamer-primer complexs on the surface of $\mathrm{MBs}, \mathrm{A} 1=1.31$, V0 represents the volume of aptamer-primer complexs $(\mu \mathrm{L}), \mathrm{V} 0=200 \mu \mathrm{L}$.

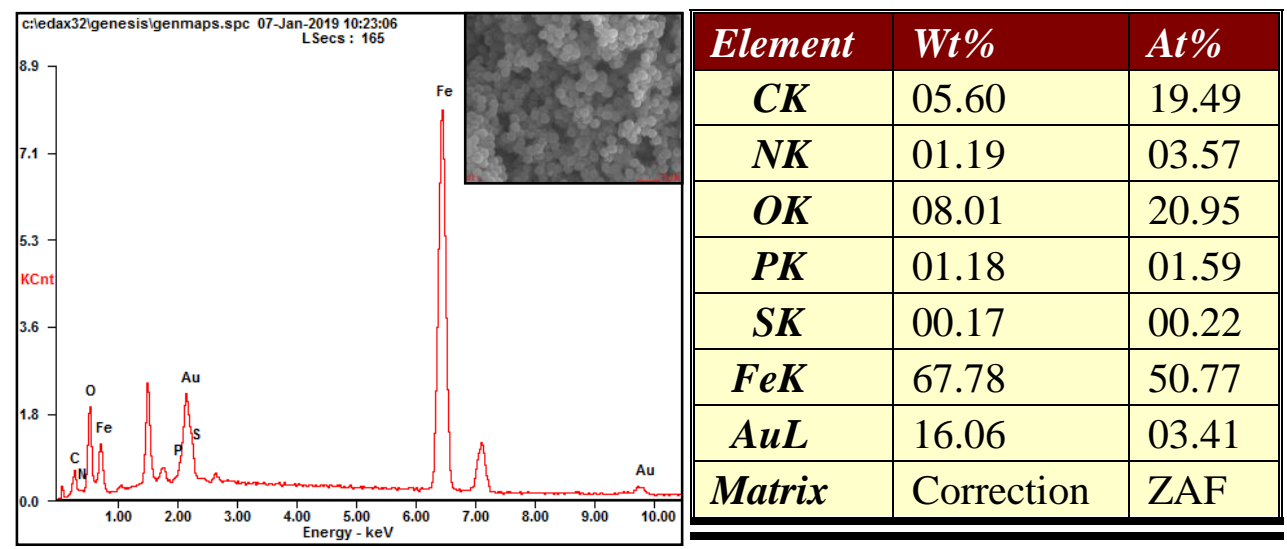

Fig. S2. The EDX of encoded magnetic beads aptamer probes (MBs-dsDNA). 

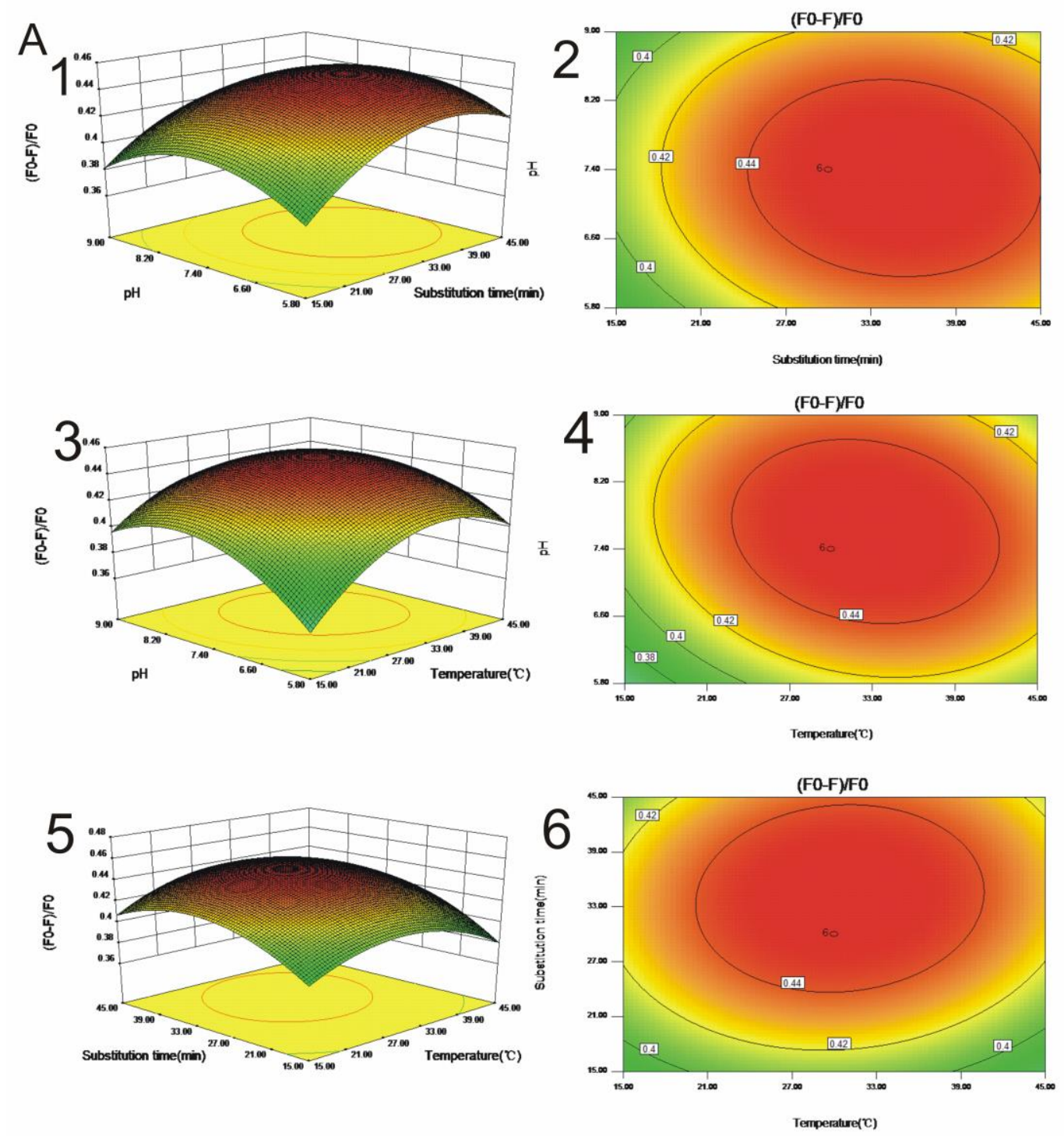

Fig. S3A. Optimization of experimental conditions for KANA. The response surface plots (left) and their corresponding contour plots (right) showing the effect of (2) pH and targets substitution reaction time, (4) $\mathrm{pH}$ and temperature, (6) targets substitution reaction time and temperature by the proposed aptasensor with $\mathrm{MC}$. 

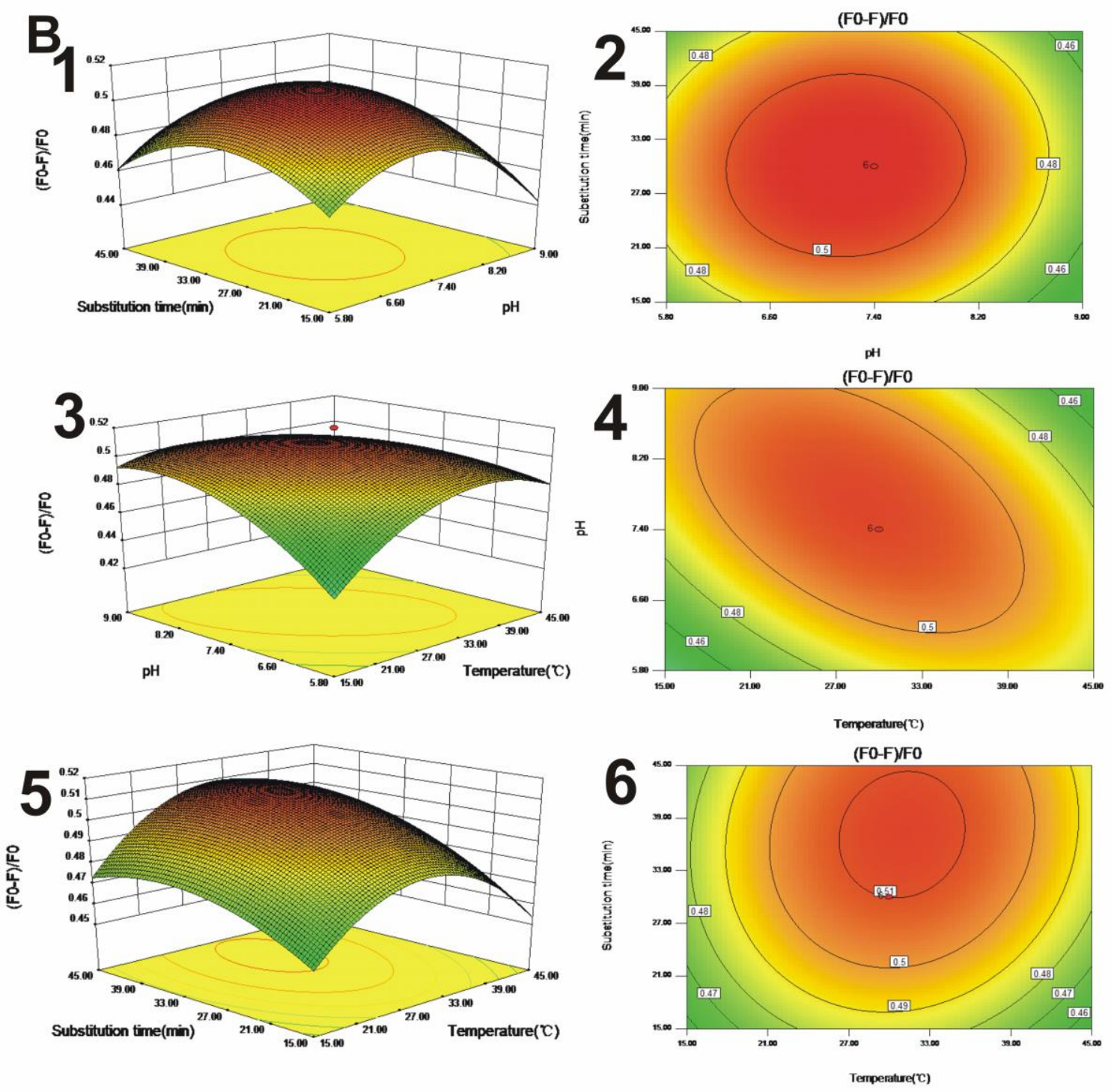

Fig. S3B. Optimization of experimental conditions for E2. The response surface plots (left) and their corresponding contour plots (right) showing the effect of (2) $\mathrm{pH}$ and targets substitution reaction time, (4) $\mathrm{pH}$ and temperature, (6) targets substitution reaction time and temperature by the proposed aptasensor with $\mathrm{MC}$. 

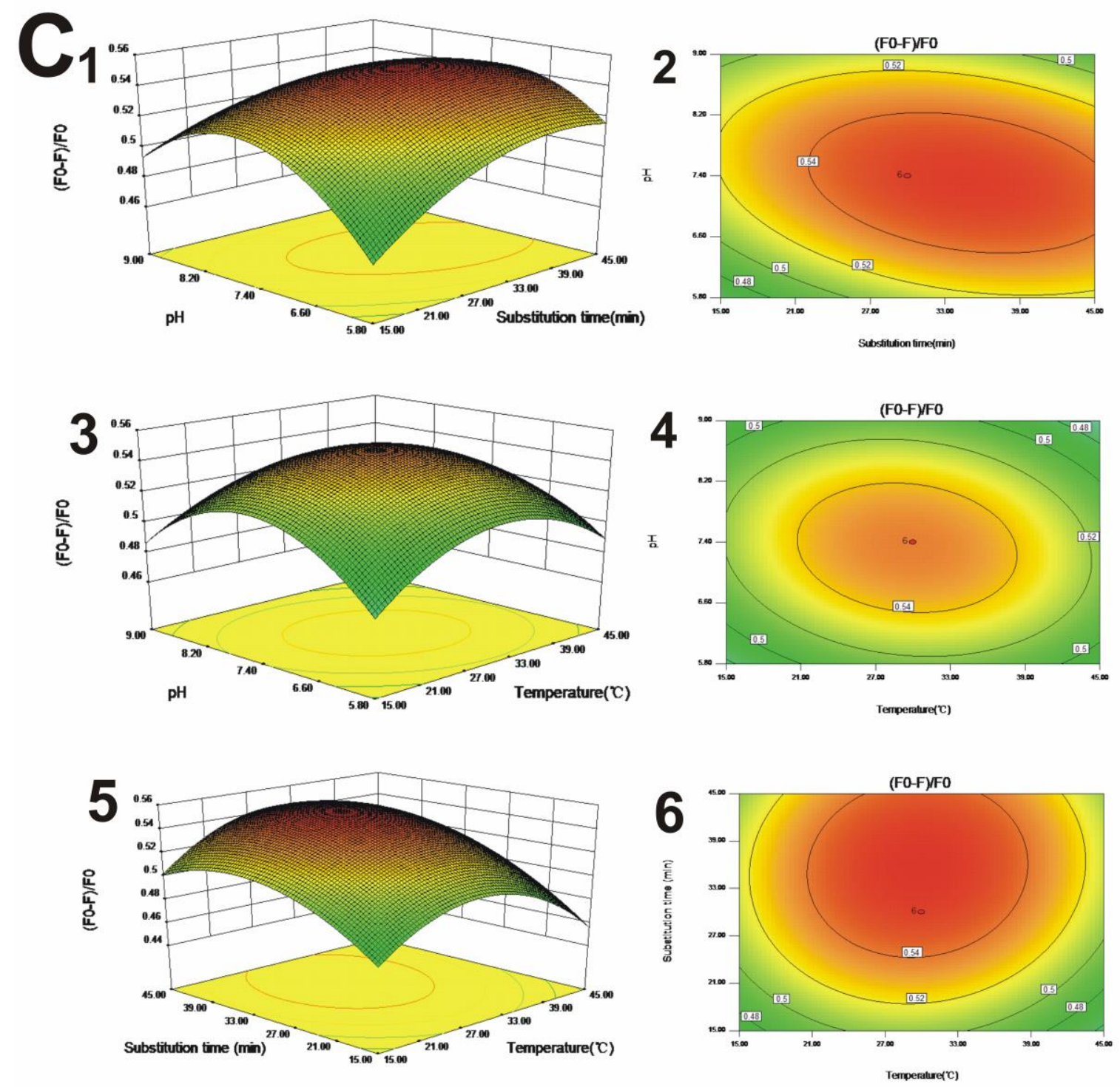

Fig. S3C. Optimization of experimental conditions for $\mathrm{Pb}^{2+}$. The response surface plots (left) and their corresponding contour plots (right) showing the effect of (2) pH and targets substitution reaction time, (4) $\mathrm{pH}$ and temperature, (6) targets substitution reaction time and temperature by the proposed aptasensor with $\mathrm{MC}$. 


\section{The explanation of purpose of gold nanoparticles and MBs}

Because of the biological activity and easy assembling, the gold nanoparticles and MBs were used to prepare the detection system. Although gold nanoparticles and MBs are expensive, they can be reusable for at least 30 times in the experiment (Fig. S4). Because of the MBs have large specific area and enough sites for immobilizing large amounts of SH-DNAs, they can be reused for many times. After 30 times, the MBs can be renewed easily by self-assembling procedures. In brief, the magnetic capture probes (MBs-dsDNA) after reaction were heated at $95{ }^{\circ} \mathrm{C}$ to release the mHCR products then cooled to $0{ }^{\circ} \mathrm{C}$. The surplus magnetic beads@primers be reformed by soaking in the solution containing $200 \mu \mathrm{L} 5 \mu \mathrm{M}$ aptamers to form MBs-dsDNA.

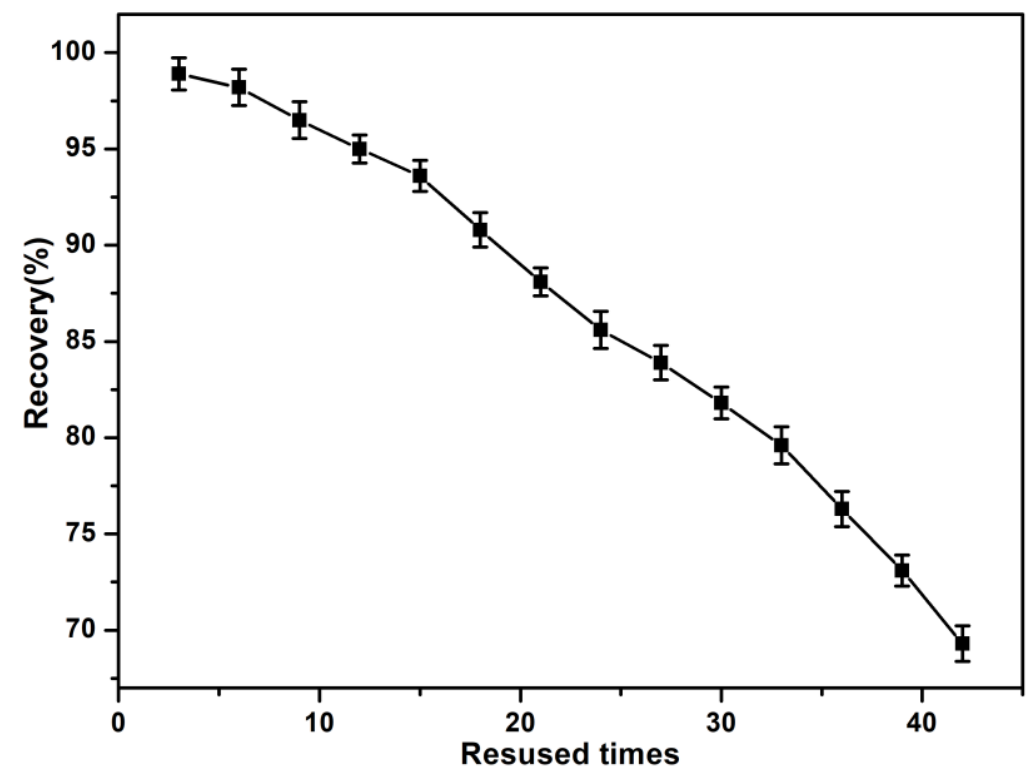

Fig.S4. The reused times of the MBs. 
In addition, we also studied the reuse performance of microfluidic chip. As shown in Fig. S5, the recovery rate of the targets did not decrease significantly (more than $80 \%$ ) when the chip was reused for 4000 times, the cost for a single detection was as low as 0.1 dollars. The result indicated that this chip is cost effective.

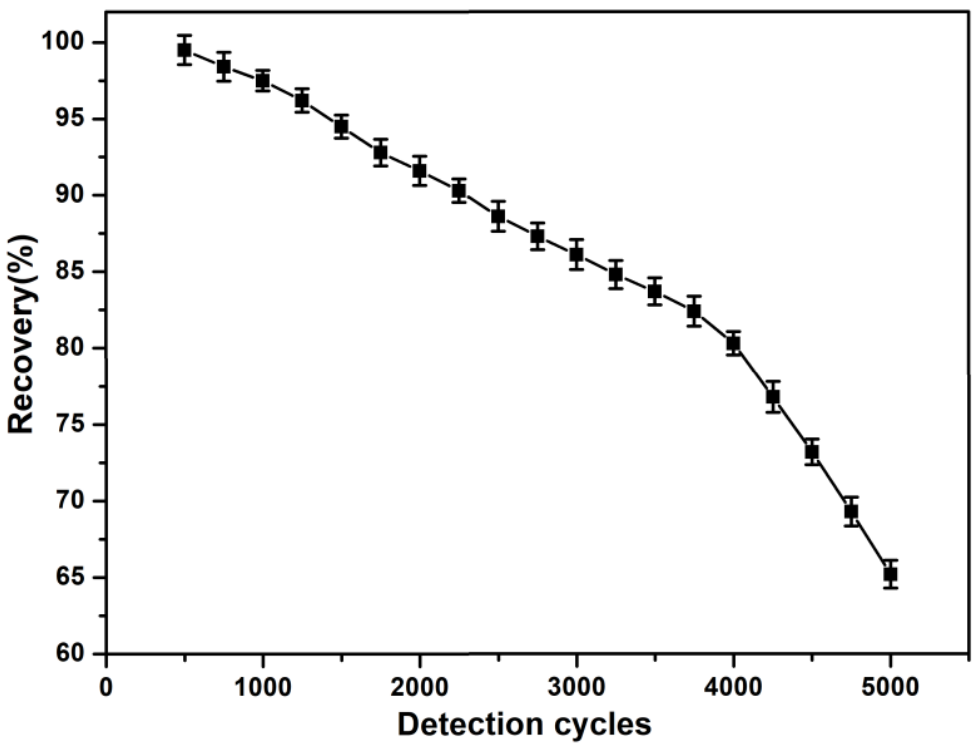

Fig. S5. The reused times of the microfluidic chip. 

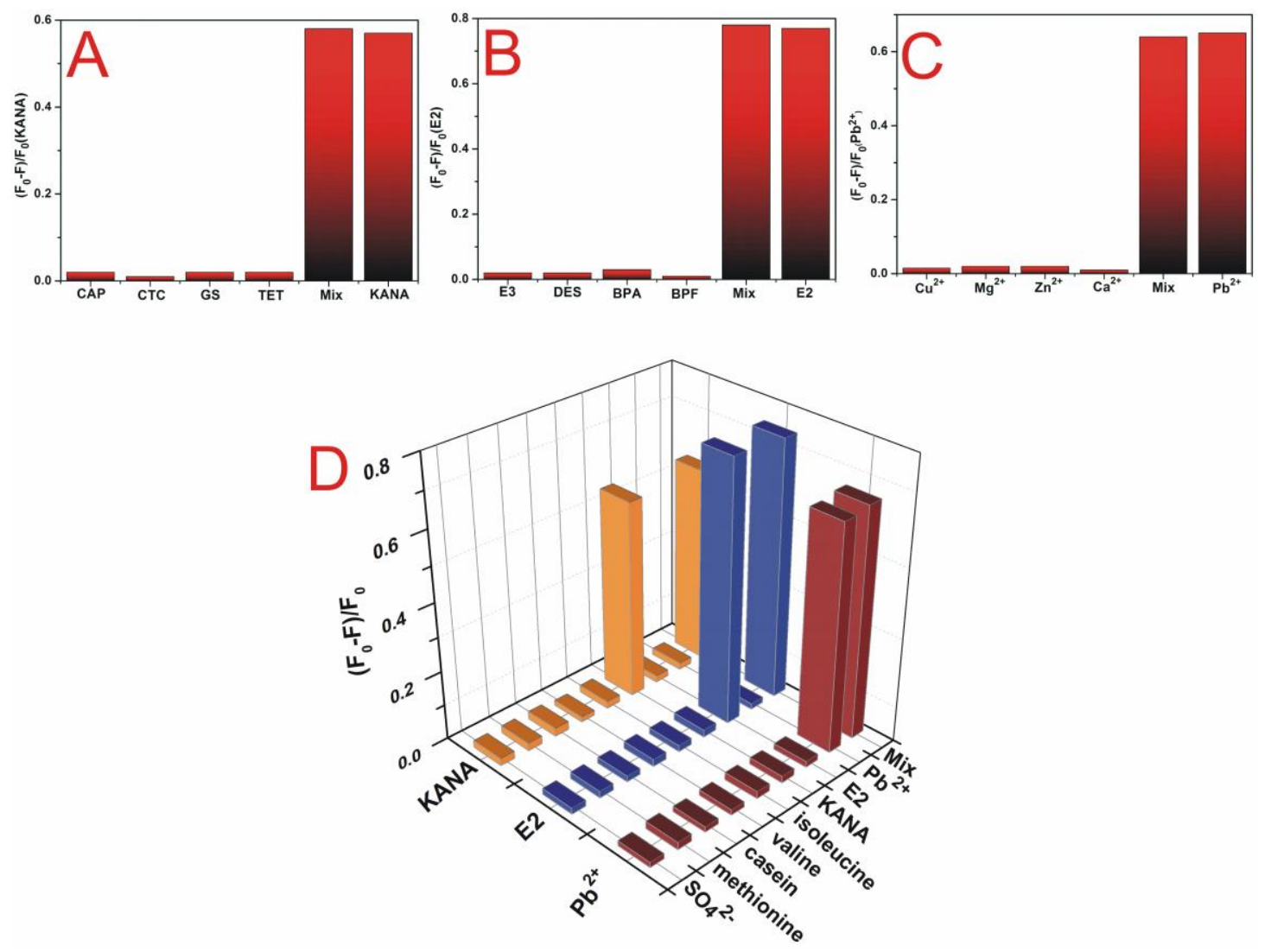

Fig. S6. Selectivity and interference of the proposed sensor towards three targets KANA, E2 and $\mathrm{Pb}^{2+}$. (A) the results of detecting other antibiotics $(10 \mathrm{nmol} / \mathrm{L}$ of the other antibiotics, $0.1 \mathrm{nmol} / \mathrm{L}$ of KANA). (B) Selectivity of the sensing method against other estrogen. (10 nmol/L of the other estrogen, $0.1 \mathrm{nmol} / \mathrm{L}$ of E2). (C) Selectivity test toward $\mathrm{Pb}^{2+}$ and other metal ions. The concentrations for other metal ions were all $10 \mathrm{nmol} / \mathrm{L}$. (D) Anti-interference of the assay against the interfering substances. Concentrations of KANA, E2 and $\mathrm{Pb}^{2+}$ were $0.1 \mathrm{nmol} / \mathrm{L}$, respectively. The concentration of other substances was $100 \mathrm{nmol} / \mathrm{L}$, respectively. The error bars were based on three repetitive experiments. 
Table S2A. The developed method and ELISA method for KANA detection ( $\overline{\mathrm{x}} \pm \mathrm{s}$, $\mathrm{n}=3$ ).

\begin{tabular}{lllllll}
\hline \multirow{2}{*}{ Sample } & $\begin{array}{l}\text { Added } \\
(\mathrm{nmol} / \mathrm{L})\end{array}$ & $\begin{array}{l}\text { Proposed } \\
\text { method } \\
\text { Detection } \\
(\mathrm{nmol} / \mathrm{L})\end{array}$ & RSDs $\%$ & $\begin{array}{l}\text { ELISA } \\
\text { Detection } \\
(\mathrm{nmol} / \mathrm{L})\end{array}$ & RSDs \% & Recovery (\%) \\
\cline { 2 - 7 } & \multicolumn{7}{c}{ KANA } & & \\
\hline \multirow{2}{*}{ Milk1 } & 0.5 & $0.517 \pm 0.018$ & 4.03 & $0.508 \pm 0.011$ & 5.31 & 103.4 \\
& 5 & $4.939 \pm 0.029$ & 4.26 & $5.044 \pm 0.035$ & 4.05 & 98.78 \\
Milk2 & 0.5 & $0.512 \pm 0.015$ & 4.01 & $0.522 \pm 0.013$ & 4.23 & 102.4 \\
& 5 & $5.031 \pm 0.054$ & 4.84 & $5.091 \pm 0.034$ & 4.43 & 100.6 \\
Fish1 & 0.5 & $0.509 \pm 0.016$ & 4.32 & $0.519 \pm 0.017$ & 5.08 & 101.8 \\
& 5 & $5.017 \pm 0.035$ & 4.21 & $5.041 \pm 0.039$ & 4.23 & 100.3 \\
Fish2 & 0.5 & $0.521 \pm 0.019$ & 4.58 & $0.516 \pm 0.012$ & 4.19 & 104.2 \\
& 5 & $5.013 \pm 0.042$ & 3.89 & $4.995 \pm 0.061$ & 4.11 & 100.3 \\
Pork1 & 0.5 & $0.499 \pm 0.019$ & 4.11 & $0.503 \pm 0.015$ & 3.77 & 99.82 \\
& 5 & $5.105 \pm 0.046$ & 4.29 & $5.048 \pm 0.014$ & 3.99 & 102.1 \\
Pork2 & 0.5 & $0.501 \pm 0.019$ & 3.97 & $0.502 \pm 0.015$ & 4.02 & 100.2 \\
\hline
\end{tabular}

Table S2B. The developed method and HPLC method for E2 detection ( $\bar{x} \pm s, n=3)$.

\begin{tabular}{|c|c|c|c|c|c|c|}
\hline \multirow[t]{2}{*}{ Sample } & $\begin{array}{l}\text { Added } \\
(\mathrm{nmol} / \mathrm{L})\end{array}$ & $\begin{array}{l}\text { Proposed } \\
\text { method } \\
\text { Detection } \\
(\mathrm{nmol} / \mathrm{L})\end{array}$ & RSDs \% & $\begin{array}{l}\text { HPLC } \\
\text { Detection } \\
(\mathrm{nmol} / \mathrm{L})\end{array}$ & RSDs $\%$ & Recovery (\%) \\
\hline & \multicolumn{6}{|c|}{ E2 } \\
\hline \multirow{2}{*}{ Milk1 } & 0.1 & $0.104 \pm 0.011$ & 4.38 & $0.108 \pm 0.013$ & 3.99 & 104.2 \\
\hline & 1 & $0.984 \pm 0.054$ & 4.09 & $0.904 \pm 0.064$ & 4.43 & 98.44 \\
\hline \multirow{2}{*}{ Milk2 } & 0.1 & $0.104 \pm 0.015$ & 4.74 & $0.099 \pm 0.016$ & 4.91 & 104.4 \\
\hline & 1 & $1.005 \pm 0.044$ & 4.62 & $0.991 \pm 0.045$ & 4.89 & 100.5 \\
\hline \multirow{2}{*}{ Fish1 } & 0.1 & $0.098 \pm 0.011$ & 4.57 & $0.109 \pm 0.013$ & 5.03 & 98.12 \\
\hline & 1 & $1.005 \pm 0.056$ & 4.87 & $1.107 \pm 0.079$ & 4.09 & 100.5 \\
\hline \multirow{2}{*}{ Fish2 } & 0.1 & $0.104 \pm 0.015$ & 4.63 & $0.099 \pm 0.012$ & 3.98 & 104.4 \\
\hline & 1 & $1.006 \pm 0.054$ & 3.91 & $0.987 \pm 0.049$ & 4.01 & 100.6 \\
\hline \multirow{2}{*}{ Pork 1} & 0.1 & $0.106 \pm 0.019$ & 3.89 & $0.109 \pm 0.011$ & 4.02 & 106.1 \\
\hline & 1 & $1.001 \pm 0.038$ & 4.25 & $0.981 \pm 0.043$ & 4.54 & 100.1 \\
\hline \multirow{2}{*}{ Pork2 } & 0.1 & $0.091 \pm 0.015$ & 4.34 & $0.092 \pm 0.017$ & 4.42 & 91.15 \\
\hline & 1 & $1.021 \pm 0.039$ & 4.23 & $1.011 \pm 0.053$ & 3.97 & 102.1 \\
\hline
\end{tabular}


Table S2C. The developed method and ICP-MS method for $\mathrm{Pb}^{2+}$ detection ( $\overline{\mathrm{x}}_{\mathrm{s}}$, $\mathrm{n}=3$ ).

\begin{tabular}{lllllll}
\hline \multirow{2}{*}{ Sample } & $\begin{array}{l}\text { Added } \\
(\mathrm{nmol} / \mathrm{L})\end{array}$ & $\begin{array}{l}\text { Proposed method } \\
\text { Detection } \\
(\mathrm{nmol} / \mathrm{L})\end{array}$ & $\mathrm{RSDs} \%$ & $\begin{array}{l}\text { ICP-MS } \\
\text { Detection } \\
(\mathrm{nmol} / \mathrm{L})\end{array}$ & RSDs \% & Recovery (\%) \\
\cline { 2 - 6 } Milk1 & 0.1 & $0.103 \pm 0.012$ & 4.67 & $0.098 \pm 0.015$ & 5.03 & 103.4 \\
& 1 & $0.983 \pm 0.055$ & 4.46 & $0.101 \pm 0.043$ & 4.31 & 98.32 \\
Milk2 & 0.1 & $0.104 \pm 0.013$ & 4.83 & $0.093 \pm 0.016$ & 5.12 & 104.2 \\
& 1 & $1.003 \pm 0.044$ & 4.14 & $0.987 \pm 0.065$ & 4.03 & 100.3 \\
Fish1 & 0.1 & $0.098 \pm 0.012$ & 4.35 & $0.097 \pm 0.011$ & 4.42 & 98.14 \\
& 1 & $1.002 \pm 0.046$ & 3.81 & $1.001 \pm 0.039$ & 4.65 & 100.2 \\
Fish2 & 0.1 & $0.101 \pm 0.011$ & 4.08 & $0.096 \pm 0.012$ & 3.92 & 101.2 \\
& 1 & $1.005 \pm 0.055$ & 4.77 & $0.971 \pm 0.045$ & 3.75 & 100.5 \\
Pork1 & 0.1 & $0.101 \pm 0.009$ & 4.34 & $0.102 \pm 0.011$ & 4.22 & 101.3 \\
& 1 & $0.961 \pm 0.039$ & 3.89 & $1.003 \pm 0.042$ & 4.32 & 96.14 \\
Pork2 & 0.1 & $0.097 \pm 0.019$ & 4.53 & $0.093 \pm 0.014$ & 4.51 & 97.21 \\
\hline
\end{tabular}

